\title{
Emerging Roles for Phase Separation of RNA-Binding Proteins in Cellular Pathology of ALS
}

\author{
Katarina Milicevic ${ }^{1 \dagger}$, Branislava Rankovic ${ }^{2 \dagger}$, Pavle R. Andjus ${ }^{1 \dagger}$, Danijela Bataveljic ${ }^{1 *}$ and \\ Dragomir Milovanovic ${ }^{2 *}$
}

${ }^{1}$ Center for Laser Microscopy, Faculty of Biology, Institute of Physiology and Biochemistry "Ivan Djaja", University of Belgrade, Belgrade, Serbia, ${ }^{2}$ Laboratory of Molecular Neuroscience, German Center for Neurodegenerative Diseases (DZNE), Berlin, Germany

\section{OPEN ACCESS}

Edited by:

May Khanna,

University of Arizona, United States

Reviewed by:

Tetsuya Akiyama,

Stanford University, United States Liberty Francois-Moutal, University of Arizona, United States

${ }^{*}$ Correspondence: Danijela Bataveliic bataveljic.danijela@bio.bg.ac.rs Dragomir Milovanovic dragomir.milovanovic@dzne.de

${ }^{+}$These authors have contributed equally to this work

Specialty section: This article was submitted to

Cellular Biochemistry,

a section of the journal Frontiers in Cell and Developmental Biology

Received: 20 December 2021 Accepted: 24 January 2022 Published: 17 February 2022

Citation:

Milicevic $K$, Rankovic B, Andjus PR, Batavelic D and Milovanovic D (2022) Emerging Roles for Phase Separation of RNA-Binding Proteins in Cellular

Pathology of ALS.

Front. Cell Dev. Biol. 10:840256. doi: 10.3389/fcell.2022.840256
Liquid-liquid phase separation (LLPS) is emerging as a major principle for the mesoscale organization of proteins, RNAs, and membrane-bound organelles into biomolecular condensates. These condensates allow for rapid cellular responses to changes in metabolic activities and signaling. Nowhere is this regulation more important than in neurons and glia, where cellular physiology occurs simultaneously on a range of time- and length-scales. In a number of neurodegenerative diseases, such as Amyotrophic Lateral Sclerosis (ALS), misregulation of biomolecular condensates leads to the formation of insoluble aggregates - a pathological hallmark of both sporadic and familial ALS. Here, we summarize how the emerging knowledge about the LLPS of ALS-related proteins corroborates with their aggregation. Understanding the mechanisms that lead to protein aggregation in ALS and how cells respond to these aggregates promises to open new directions for drug development.

Keywords: liquid-liquid phase separation, FUS, TDP-43, RNP aggregates, stress granule, neurons, amyotrophic lateral sclerosis

\section{INTRODUCTION}

Amyotrophic Lateral Sclerosis (ALS) is a fatal neurodegenerative disease caused by the selective death of motor neurons in the spinal cord and brain. The onset of symptoms in ALS patients is observed at the age between 51 and 66 years, usually displayed as muscle weakness and impaired ability to control swallowing and speaking (Brown and Al-Chalabi, 2017; Longinetti and Fang, 2019). Most of the ALS cases are sporadic (sALS), whereas approximately $10 \%$ of cases represent a familial form (fALS) (Kim et al., 2020). The first identified mutation linked to ALS was in the gene encoding cytoplasmic enzyme superoxide dismutase 1 (SOD1) (Rosen et al., 1993). Currently, over 40 additional genes related to ALS have been discovered with the most common genetic mutation in the chromosome nine open reading frame 72 (C9orf 72 ) gene observed in $~ 40 \%$ of fALS patients (Taylor et al., 2016). A number of ALS-related genes encode RNA-binding proteins (RBPs) including TAR DNA-binding protein 43 (TDP-43), fused in sarcoma (FUS), heterogeneous nuclear ribonucleoprotein A1 (hnRNPA1) and T-cell restricted intracellular antigen-1 (TIA-1) (Zhao et al., 2018; Kim et al., 2021). RBPs play an important role in the regulation of RNA metabolism (Nussbacher et al., 2015, 2019; Xue et al., 2020) and many of them are prone to undergo liquid-liquid phase separation (LLPS) and form fluid condensates (Lin et al., 2015; Mittag and Parker, 2018). Notably, RBPs display tendency to aggregate and their presence is detected in the intracellular cytoplasmic aggregates, the key element in degenerating motor neurons of patients with 


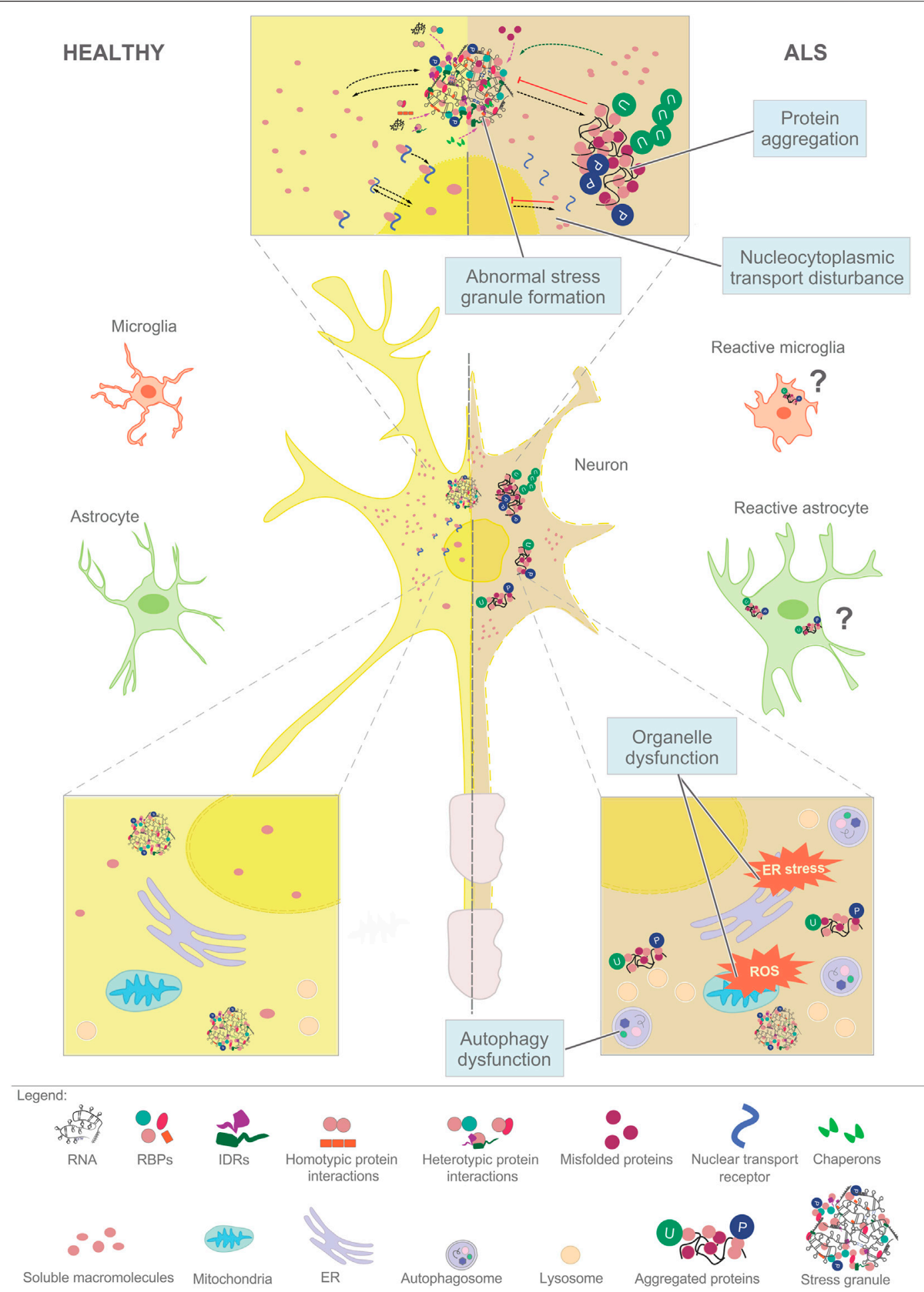

FIGURE 1 | Aberrant phase separation of RNA-binding proteins (RBPs) plays a central role in the cellular pathology of ALS. Macromolecules such as RNAs and proteins assemble in dynamic and reversible condensates in healthy neurons and glia (left), that mature into stress granules (top, center) and insoluble aggregates destined for degradation (right). The cellular pathways that affect the LLPS of RNPs include (i) nucleocytoplasmic transport, (ii) assembly of stress granules, (iii) aggregation driven by the accumulation of misfolded proteins, (iv) organellar dysfunction that leads to ROS and persistent stress, and (v) failed autophagy-lysosome pathway. Similar pathways might play a role in glial cells. 
ALS (Blokhuis et al., 2013). However, exact mechanisms driving the protein aggregation are still unknown.

In this review, we outline current knowledge on the ALSrelated protein condensations in neurons and glia. In particular, we emphasize how disrupted LLPS of RNAbinding proteins lead to their aggregation. For the roles of two well-studied RBPs, TDP-43 and FUS in frontotemporal dementia, we refer to the review by Carey and Guo within this Special Issue. The aberrant RBP condensates can even trap folded proteins which do not undergo LLPS such as SOD1 (Mateju et al., 2017; Pakravan et al., 2021) and alter the intracellular organelle trafficking (Ling et al., 2019; Trnka et al., 2021). Understanding the mechanisms how LLPS of several ALS-associated RBPs corroborates with the intracellular organelle trafficking (Figure 1) opens novel directions for disease treatment.

\section{PROTEIN AGGREGATES ARE CLINICAL HALLMARK IN ALS}

A common feature of both sALS and fALS is the presence of protein aggregates in the cytosol of neurons and glia. Early studies reported aggregates that are ubiquitin-positive dense, irregular or filamentous (skein-like) inclusions in the spinal cord motoneurons in fALS and sALS patients (Leigh et al., 1991). DNA/RNA-binding proteins, TDP-43 and FUS are normally localized in the nucleus where they act as RNA metabolism regulators (Andersson et al., 2008; Buratti and Baralle, 2008). In ALS, TDP-43 and FUS mislocalize from the nucleus to the cytoplasm where they aggregate and appear in ALS-related inclusions (Blokhuis et al., 2013). Within aggregates, TDP-43 is frequently post-translationally modified by ubiquitination and/ or phosphorylation (Neumann et al., 2006, 2009; Mackenzie et al., 2007; Hasegawa et al., 2008; Bodansky et al., 2010; Brettschneider et al., 2013), aberrant cleavage (Neumann et al., 2006; Altman et al., 2021) and protein misfolding (Prasad et al., 2019). On the other hand, both mutated and wild-type SOD1 are found in the cytosolic aggregates in the spinal cord and cortical motoneurons of fALS patients bearing SOD1 mutation (Jonsson et al., 2004, 2008). Protein aggregates are also identified in glial cells surrounding degenerating motor neurons. SOD1 aggregates are present in astrocytes and microglia (Jonsson et al., 2004; Stamenković et al., 2017) and are related to a change in cell morphology (Stamenković et al., 2017). Similarly, TDP-43 inclusions are found in the glial cells of both gray and white matter spinal cord, in sALS and some fALS patients (Arai et al., 2006; Mackenzie et al., 2007; Brettschneider et al., 2013) suggesting the important role of glial cells in ALS pathology (Vahsen et al., 2021).

Protein aggregates in ALS are heterogenous. For example, SOD1 is occasionally found in the aggregates in motoneurons of ALS patients with C9orf72 and FUS mutations (Forsberg et al., 2019). TDP-43-positive inclusions were identified in fALS patients with C9orf72 expansion (Collins et al., 2012), but not in patients bearing FUS or SOD1 mutations (Mackenzie et al., 2007; Tan et al., 2007; Vance et al., 2009) indicating distinct pathways of aggregate formation. However, studies in SOD1 ${ }^{\mathrm{A} 4 \mathrm{~T}}$ patients point to the interaction of SOD1 and TDP-43 as confirmed by their co-immunoprecipitation (Volkening et al., 2009). The data on ALS patients only provide the histopathological picture at the terminal stage of the disease. Nonetheless, induced pluripotent stem cells (iPSCs) derived from patient fibroblasts recapitulate protein pathology successfully (Mattis and Svendsen, 2011; Burkhardt et al., 2013; Fujimori et al., 2018). iPSC-derived motoneurons from patients carrying FUS or TDP-43 mutations show mislocalization of mutated proteins into the cytoplasm, their phosphorylation (Fujimori et al., 2018), and aggregate formation (Bilican et al., 2012; Egawa et al., 2012; Fujimori et al., 2018). iPSC-derived neurons from patients with sALS display a presence of cytosolic and intranuclear hyperphosphorylated TDP-43 aggregates similar to those in sALS post mortem tissues (Burkhardt et al., 2013; Fujimori et al., 2018). Astrocytes generated from iPSCs harboring TDP-43 mutation show elevated levels of cytoplasmic TDP-43 and increased astrocytic cell death (Serio et al., 2013).

Several mechanisms have been proposed to underlie ALS pathology, including oxidative stress, mitochondrial dysfunction, stress at the endoplasmic reticulum (ER), disruption of RNA metabolism, neuroinflammation, glutamate excitotoxicity (rev. in Taylor et al., 2016; Mejzini et al., 2019). They are all linked to the presence of intracellular protein aggregates, which are often composed of RNA-binding proteins, able to undergo liquid-liquid phase separation (LLPS) (Molliex et al., 2015; Patel et al., 2015) (Figure 1).

\section{LIQUID-LIQUID PHASE SEPARATION: MECHANISM FOR ASSEMBLY OF RNP GRANULES}

LLPS is a thermodynamic process in which two (or more) components demix from a homogenous solution to form two or more distinct phases. In the context of cell biology, LLPS is a mechanism where biomolecules demix from a crowded cytosol or nucleoplasm to form distinct compartments referred to as biomolecular condensates. The critical features of biomolecular condensation include multivalent, low-affinity interactions of biomolecules present at high local concentrations. Thus far, RNA-RNA, RNA-protein and protein-protein interactions (Banani et al., 2017; Mittag and Parker, 2018; Van Treeck et al., 2018) are all shown to phase separate. Moreover, the entire pools of membrane-bound organelles can actively assemble in mesoscale compartments through LLPS such as clusters of synaptic vesicles (Milovanovic et al., 2018; Hoffmann et al., 2021) and stacks of Golgi apparatus (Rebane et al., 2020; Ziltener et al., 2020).

LLPS emerged as a mechanism for dynamic and reversible assembly of ribonucleoprotein (RNP) complexes (Han et al., 2012; Brangwynne, 2013; Lin et al., 2015; Molliex et al., 2015; Banani et al., 2017; Mittag and Parker, 2018). Number of functionally distinct RNP granules is suggested to undergo LLPS, including cytoplasmic RNP granules, processing (P)-bodies and stress granules (SGs) - sites of 
TABLE 1 | An overview of ALS-linked mutations in LLPS-related proteins.

\section{Protein}

Mutations

implicated in ASL
Mutation region

ANXA11

(Annexin A11)

ATXN2

(Ataxin-2)

hnRNPA1

(Heterogeneous nuclear

ribonucleoprotein A1)

hnRNPA2/B1

(Heterogeneous nuclear

ribonucleoprotein A2/B1)

FUS

(Fused in sarcoma)

TAF15

(TATA-box binding protein associated factor 15)

TDP-43

(TAR DNA binding protein 43)

A90V

D169G

K263E" , N267S

G287S, G290A, S292N, G294A, G294V, G295R, G295S, G298S, M311V, A315T, A321V, A321G, Q331K", S332N, G335D, M337V\#, Q343R\#, N345K\#, G348C,

G348V,N352T, N352S, R361S\#, P363A, Y374X, N378D, S379P, S379C, A382T, A382P, I383V, G384R, N390D\#, N390S, S393L

LCD; NTD Q97X, V128M, G137R, G175R', G189E V208L, G228Lfs29, S229R, R235Q\#, A293V,R302C, I307M, T321N, R346C, Q362L, A367V, L383_V392del, , R456H, I457V, G491R

polyQ repeats of different length

S57del, G144E", G154E", G156D", G156E", G187S", G191S, R216C, G225V*, G230C", R234C, R234L,

S402 P411delinsGGGG

S462F, G466VfsX14

R495X, G507D, K510E, S513P, R514G, R514S, G515C 17Q, H517P, R518G, R518K, R521G, R521H, R521C,

A31T

M368T, D386N, R388H, G391E\#, R395Q, R408C", G452E, G464 G471del, G473E, R474_D481del

$\mathrm{TIA}-1$

(T-cell-restricted intracellular $\quad \mathrm{P} 362 \mathrm{~L}^{\# \bullet}, \mathrm{A} 381 \mathrm{~T}^{\# \bullet}$, E384K $\mathrm{K}^{\#}$ antigen-1)
ANX homology

domains (1-4)

PolyQ region within NTD 166-187

Prion-like domain; CTD

LCD; CTD

LCD; NLS; CTD

LCD; CTD

Extension on CTD

LCD; CTD

Prion-like domain; NTD

RGG1 motif RGG2 motif NLS; CTD

Prion-like domain; NTD

LCD; CTD

NLS; NTD
RRM1
RRM2

Prion-like domain; CTD

\section{Source in addition to}

Uniprot
Smith et al. (2017); Tsai et al. (2018); Zhang et al. (2018); Nahm et al., 2020

Smith et al. (2017); Tsai et al. (2018); Zhang et al. (2018); Liu et al. (2019); Nahm et al. (2020)

Chiò et al. (2015); Blokhuis et al. (2016); Sproviero et al. (2017)

Molliex et al. (2015); Liu et al. (2016); Beijer et al. (2021)

Kim et al. (2013); Gilpin et al. (2015); Liu et al. (2016)

Liu et al. (2016); Naruse et al. (2018)

Beijer et al. (2021)

Beijer et al. (2021)

Kim et al. (2013)

Belzil et al. (2009); Kwiatkowski et al. (2009); Ticozzi et al. (2009); Corrado et al. (2010); Rademakers et al. (2010); Merner et al. (2012); Nomura et al. (2014); Patel et al. (2015); Niaki et al. (2020) DeJesus-Hernandez et al. (2010)

DeJesus-Hernandez et al. (2010); Groen et al. (2010) Kwiatkowski et al. (2009); Corrado et al. (2010); Dormann et al. (2010); Yan et al. (2010); Gal et al. (2011); Niu et al. (2012); Nomura et al. (2014)

Ticozzi et al. (2011b)

Couthouis et al. (2011); Ticozzi et al. (2011b)

Winton et al. (2008); Chiang et al. (2012)

Kabashi et al. (2008); Nonaka et al. (2009); Austin et al. (2014)

Kabashi et al. (2008); Corrado et al. (2009); Austin et al. (2014)

Sreedharan et al. (2008); Van Deerlin et al. (2008); Gitcho et al. (2008); Kabashi et al. (2008); Bäumer et al. (2009); Lemmens et al. (2009); Corrado et al. (2009); Daoud et al. (2009); Johnson et al. (2009); Kamada et al. (2009); Ling et al. (2010); Barmada and Finkbeiner, (2010); Xiong et al. (2010); Elden et al. (2010); Kirby et al. (2010); Ticozzi et al. (2011a); Chiang et al. (2012); Lattante et al. (2012); Zou et al. (2012)

Hackman et al. (2013); Mackenzie et al. (2017)

CTD, C-terminal domain; NTD, N-terminal domain; LCD, low-complexity domain; RRM, RNA recognition motif; NLS, nuclear localization signal; RGG, arginine-glycine-glycine; PolyQ, polyglutamine.

\#LLPS propensity and/or aggregation affected; SG dynamics affected.

translationally silenced mRNAs and/or RNA degradation (Decker and Parker, 2012), neuronal granules-crucial for mRNA packing, translational control, and axonal transport (Fernandopulle et al., 2021).

The intrinsically disordered regions (IDRs)—amino acid sequences that do not fold in any specific secondary or tertiary structure-play a central role in RNP granule assembly and dynamics. For example, the missense mutation in TIA-1 IDR inhibits RNP granule disassembly (Mackenzie et al., 2017) and promotes the accumulation of non-dynamic RNP granules enriched in insoluble TDP-43 (Mackenzie et al., 2017). RNP granule formation can be facilitated by IDR interactions via local 
structures such as the $\alpha$-helix of C-terminal domain of TDP-43 essential for its LLPS (Conicella et al., 2016, 2020) which has the propensity to self-associate. Also, IDR of FUS forms heterotypic interactions with GFP-fused IDR either of FUS or other proteins such as hnRNPA1 (Kato et al., 2012). Moreover, ALS linked mutations are very often located in the IDRs of LLPS related proteins (for details, see Table 1) altering their LLPS propensity and/or RNP granule dynamics.

Reversibility is a key feature of biomolecular condensates such as RNPs, with post-translational modifications playing a key role in regulating this process (Kato et al., 2012; Monahan et al., 2017; Wang et al., 2018; Hofweber and Dormann, 2019; Schisa and Elaswad, 2021). Phosphorylation of GFP-tagged IDR of FUS impairs its retention by preformed FUS hydrogels (Han et al., 2012). Mutations in IDR that increase number of FUS phosphorylation sites impair polymerization propensity and SG recruitment (Kato et al., 2012). On the other hand, phospho-double mutants within the FUS IDR core disrupt droplet disassembly (Murray et al., 2017). Therefore, a tight balance of (de)phosphorylation determines RNP granule clearance and maintenance of their fluid state. Beyond phosphorylation, post-translational modifications play a central role in the regulation of RNA-binding proteins implicated in ALS (Hofweber and Dormann, 2019; Sternburg et al., 2021).

\section{ALS-RELATED MUTATIONS DISRUPT PHASE SEPARATION OF RNA GRANULES RESULTING IN THE FORMATION OF INSOLUBLE AGGREGATES}

\section{Nucleic Acid-Binding Proteins, FUS and TDP-43, Play a Critical Role in the Pathology of ALS}

Several fALS are associated with the missense mutations in TDP43 (Kwon et al., 2012) and FUS (Deng et al., 2014). Interestingly, ALS-related mutations in the a-helix of C-terminal disordered domain within TDP-43 disrupt LLPS of TDP-43 resulting in the formation of aggregates (Conicella et al., 2016). Moreover, TDP43 mutant RNP granules in axons of rat primary cortical neurons display increased viscosity and impaired transport dynamics compared to the wild-type RNP granules (Gopal et al., 2017). Similarly, optogenetic enhancement of TDP-43 oligomerization accelerates ALS-related pathologies in the spinal motor neurons (Asakawa et al., 2020).

Another ALS-linked protein, FUS, has been reported to shuttle between nucleus and cytoplasm in a highly dynamic manner (Patel et al., 2015). In the nucleus, FUS enriches at the transcriptional sites or sites of DNA damage, while upon heat shock, it relocates to SGs in the cytoplasm (Bosco et al., 2010; Rulten et al., 2014; Patel et al., 2015). This relocation of FUS is affected in ALS patients where FUS aggregates in cytoplasmic inclusions (Dormann et al., 2010). FUS undergoes LLPS (Kato et al., 2012; Patel et al., 2015) and this process is abolished in FUS mutant lacking N-terminal IDR (Patel et al., 2015). ALS-linked mutations in the IDR of FUS (e.g., G156E) promote aggregate formation (Nomura et al., 2014) through molecular aging of FUS condensates that accelerate the conversion of FUS liquid droplets to fibrillar aggregates (Patel et al., 2015). Similarly, ALS-related mutations in hnRNPA1 promote fibrilization and seeding of hnRNPA1 fibrils within the fluid droplet (Molliex et al., 2015). Altogether, these studies strongly suggest that the aberrant phase transition of RNP granules is involved in the onset of ALS.

\section{RNA Buffers Phase Separation Behavior of ALS Linked RBPs}

In recent years, RNA molecules are emerging as central regulators of RNP granule formation and dynamics (rev. in Van Treeck et al., 2018; Tian et al., 2020) and can undergo phase separation (Jain and Vale, 2017). RNA molecules are critical for regulating the phase behavior of ALS-linked proteins, including FUS, TDP43 and hnRNPA1 (Banerjee et al., 2018; Maharana et al., 2018; Niaki et al., 2020). Specifically, the ratio of RNA to protein has an important role in promoting RNA droplet formation: at a low $\mathrm{RNA} /$ protein ratio, RNP droplets are prompted to form, while high RNA/protein ratios lead to droplet dissolution (ElbaumGarfinkle et al., 2015; Maharana et al., 2018). Moreover, long RNAs can act as scaffolds that further promote FUS droplet formation (Maharana et al., 2018). This implicates the importance of both RNA concentration and intrinsic features in the regulation of ALS-linked RNP granules assembly (Zhang et al., 2015; Sanchez de Groot et al., 2019). The formation of ALSlinked FUS mutant aggregates can be prevented by addition of RNA molecules in vitro (Maharana et al., 2018). In addition, ALSlinked mutations in the C-terminal domain of FUS alter RNA binding and promote formation of aggregated FUS-containing RNP complexes (Niaki et al., 2020). Altogether, these findings indicate that specific RNA sequences could prevent the aberrant aggregation of ALS-linked RBPs (Banerjee et al., 2018; Maharana et al., 2018; Niaki et al., 2020).

\section{ALS Mutations Disrupt Nuclear-Cytoplasmic Shuttle}

Disbalance between nuclear and cytoplasmic transport of ALSlinked proteins could contribute to their toxic accumulation in cytoplasmic inclusions of ALS/FTD patients. Indeed, ALSassociated mutations in nuclear localization sequences (NLS) of FUS are responsible for the disruption of FUS localization in the nucleus (Dormann et al., 2010). The FUS NLS interacts with nuclear transport receptor (NTR) Karyopherin- $\beta 2$ (Kap $\beta 2$ ) (Lee et al., 2006; Dormann et al., 2012). This interaction drives FUS nuclear import (Dormann et al., 2010) and is critical for phase separation of FUS (Hofweber et al., 2018; Yoshizawa et al., 2018). In fact, Kap $\beta 2$ also dissolve phase-separated hnRNPA1 and FUS (Guo et al., 2018). Kap $\beta 2$ specifically blocks FUS phase separation in vitro (Hofweber et al., 2018; Yoshizawa et al., 2018).

Chaperoning of FUS by Kap $\beta 2$ is mediated via RGG domain (Dormann et al., 2012), crucial for LLPS of RNA-binding proteins (Hofweber et al., 2018; Schuster et al., 2020; Wang et al., 2021). All 
RGG repeats of FUS undergo post-translational methylation by PRMT1 or PRMT8 (Scaramuzzino et al., 2013). Interestingly, it has been observed that in patients, arginine methylation of FUS is disrupted (Dormann et al., 2012; Suárez-Calvet et al., 2016) leading to the impairment of FUS LLPS and localization within SGs (Yoshizawa et al., 2018) implicating the interplay between post-translational modifications and nuclear cytoplasmic shuttle in regulating RNP distribution to different cellular compartments. Nuclear transport disruption have also been implicated in TDP-43 pathology (Chou et al., 2018). Interestingly, TDP-43 fibrils are not engaged by Kap $\beta 2$ but by Impa and Kap $\beta 1$ via its NLS. In addition, it has been shown that R-rich dipeptide repeats similar to those found in C9orf72 hexanucleotide repeats, can bind NTRs such as $\operatorname{Impa,} \operatorname{Imp} \beta$, Kap $\beta 2$ (Hutten et al., 2020) competing with NLS-containing cargos such as TDP-43. Beyond being just a signal that promotes nuclear import, NLS as well as the availability of NTRs play an anti-aggregation role, ensuring that the nuclear cargo is chaperoned and non-aggregated in the cytoplasm.

\section{STRESS GRANULE ASSEMBLY AND DYNAMICS ARE ALTERED IN ALS}

Upon exposure to stress, a pool of mRNAs recruit a set of specific RBPs, such as G3BP1 (Kedersha et al., 2013, 2016; Jain et al., 2016) and nucleate a special type of RNP granules, so-called stress granules (SGs). SGs are membraneless organelles (Kedersha et al., 2005; Baradaran-Heravi et al., 2020; Malik and Wiedau, 2020) that allow the prompt response of the cell to stress by regulating protein synthesis (Ashe et al., 2000; Besse and Ephrussi, 2008; Spriggs et al., 2010). Upon stress relief SGs disassemble allowing re-initiation of mRNA translation (Buchan and Parker, 2009; Decker and Parker, 2012; Panas et al., 2016; Baradaran-Heravi et al., 2020). SGs can also act as sites of mRNA triage, where transcripts are routed to either translation, degradation or packing (Hofmann et al., 2021).

In CNS, SG dynamics is cell-type dependent as their distribution in neurons is perinuclear while in astrocytes SGs are localized toward the cell periphery (Khalfallah et al., 2018). Nonetheless, TDP-43 is required for maintaining SG dynamics in both cell types (Aulas et al., 2012). Misregulation of SG dynamics is linked to aggregation in ALS (Li et al., 2013). Many ALS-linked proteins, including FUS, TDP-43, TIA-1, hnRNPA1, Ataxin-2, C9orf72 repeats have all been shown to localize in SGs (Nonhoff et al., 2007; Bentmann et al., 2012; Dewey et al., 2012; Li et al., 2013; Ramaswami et al., 2013; Boeynaems et al., 2017). In fact, mutations of these proteins affect the LLPS of SGs. For example dipeptides derived from C9orf72 hexanucleotide repeats not only undergo LLPS themselves (Boeynaems et al., 2017; White et al., 2019), but also affect SG dynamics in cells (Boeynaems et al., 2017).

It has been shown that molecular chaperones play an important role in preventing the assembly of aberrant SGs (Ganassi et al., 2016; Mateju et al., 2017; Lu et al., 2021; Yu et al., 2021). HSP27 and HSP70 were shown to localize in SGs containing misfolded proteins (Mateju et al., 2017). Furthermore, chemical inhibition of HSP70 increased the population of SGs containing misfolded proteins, including mutated SOD1 (Mateju et al., 2017). Moreover, HSP70 was shown to be crucial for maintaining the fluidity of anisosome-nuclear inclusions (Ganassi et al., 2016) and disassembly of TDP-43 cytoplasmic droplets (Lu et al., 2021). Reduced levels of HSP27 are reported in motor neurons of patients with TDP-43-associated ALS (Lu et al., 2021). Although SOD1 as a folded protein does not undergo LLPS, it has been shown that mutant SOD1 (mSOD1) has a tendency to accumulate in SGs in ALS (Mateju et al., 2017). Unlike wild-type, mutant SOD1 is identified in G3BP1- and TIA1 -positive SGs in the spinal cord tissue from SOD ${ }^{\mathrm{G} 93 \mathrm{~A}}$ mice and SOD1 ALS patients (Gal et al., 2016; Mateju et al., 2017; Lee et al., 2020) and contributes to the impaired dynamics of SGs (Lee et al., 2020). mSOD1 directly interacts with the RNA-binding domain of G3BP1 and affects SG dynamics as the presence of mSOD1 delayed the formation of G3BP1-positive SGs in response to osmotic stress (Gal et al., 2016). Moreover, mSOD1-containing SGs tend to increase ER stress (Rajpurohit et al., 2020). Similarly, mSOD1 interacts with TIA-1 containing SGs leading to their impaired dynamics (Lee et al., 2020).

Another important mechanism in regulating the aberrant SGs is autophagy (Ganassi et al., 2016; Mateju et al., 2017). If persistent upon removal of stress, SGs undergo the process of autophagy (Buchan et al., 2013). ALS-associated misfolded proteins are targeted to aggresomes (Kawaguchi et al., 2003) subsequently degraded by autophagy (Mateju et al., 2017). The aberrant phase separation of FUS leads to the formation of cytosolic aggregates in a concentration-dependent fashion and lysosomes are juxtaposed to these aggregates (Trnka et al., 2021). In line with these findings, increased lysosomal activity and enhanced autophagy are also reported in astrocytes derived from ALS patients (Rajpurohit et al., 2020). Recently, increased recruitment of small ubiquitinlike modifier (SUMO) ligases into the SGs is observed upon stress exposure leading to SUMOylation of proteins necessary for SG disassembly (Marmor-Kollet et al., 2020), and its disruption occurs in ALS patients.

\section{OPEN QUESTIONS AND FUTURE DIRECTIONS}

Intensive research has been focused on cellular mechanisms underlying ALS. Here we summarized the emerging roles of LLPS in cellular pathology of ALS. In particular, we highlighted TDP-43 and FUS, two proteins enriched in RNP granules. Finally, we discuss how the regulation of RNP dynamics is critical for the reversible assembly and clearance of SGs, which if not regulated, lead to aberrant phase separation and aggregation. Together, these studies open several important questions. For example, apart from neurons, emerging evidence suggests that glial cells play an important role in the ALS onset and progression (Vahsen et al., 2021). However, whether the cytosolic-nuclear dynamics of TDP-43 or the SG dynamics differ between neurons and glia remains unclear.

Another important aspect is the use of animal models of ALS (Picher-Martel et al., 2016; Morrice et al., 2018) that are a valuable 
tool to improve the selection of novel therapeutic candidates. However, many drugs that showed an efficient effect in rodents failed later in clinical trials (Moujalled and White, 2016). To date, only a few drugs are officially approved for ALS treatment (Liscic et al., 2020), which all show limited therapeutic benefit for ALS patients (Brown and Al-Chalabi, 2017), emphasizing the need for defining novel targets.

The nuclear-cytosolic shuttle promotes the development of new targets. For example, a TDP-43 A90V mutation within its NLS leads to accumulation of insoluble TDP-43 (Winton et al., 2008). Interestingly, TDP-43 NLS is a target of TDP-43 PARylation which promotes its liquid demixing (McGurk et al., 2018). These new targets need to take into account both the neurons and glia, and account for LLPS-derived mechanisms that might result in effects visible only when the backup surveillance systems fail, as in aging or upon acute stress.

Recent findings demonstrate the association of SGs with several membrane-linked compartments such as ER, lysosomes and mitochondria (Liao et al., 2019; Lee et al., 2020; Amen and Kaganovich, 2021; Trnka et al., 2021) raising the interest in SG physiological properties and their implication in ER and oxidative stress in ALS. These are precisely the mechanisms targeted by the most recent drug AMX0035 (tauroursodeoxycholic acid and sodium phenylbutyrate), which is at the late stages of approval by FDA for clinical use.

Finally, the aberrant phase-separation of RNA-binding proteins is just one side of the coin. To understand the

\section{REFERENCES}

Altman, T., Ionescu, A., Ibraheem, A., Priesmann, D., Gradus-Pery, T., Farberov, L., et al. (2021). Axonal TDP-43 Condensates Drive Neuromuscular junction Disruption through Inhibition of Local Synthesis of Nuclear Encoded Mitochondrial Proteins. Nat. Commun. 12, 6914. doi:10.1038/s41467-02127221-8

Amen, T., and Kaganovich, D. (2021). Stress Granules Inhibit Fatty Acid Oxidation by Modulating Mitochondrial Permeability. Cel Rep. 35, 109237. doi:10.1016/j. celrep.2021.109237

Andersson, M. K., Ståhlberg, A., Arvidsson, Y., Olofsson, A., Semb, H., Stenman, G., et al. (2008). The Multifunctional FUS, EWS and TAF15 ProtoOncoproteins Show Cell Type-specific Expression Patterns and Involvement in Cell Spreading and Stress Response. BMC Cel Biol. 9, 37. doi:10.1186/14712121-9-37

Arai, T., Hasegawa, M., Akiyama, H., Ikeda, K., Nonaka, T., Mori, H., et al. (2006). TDP-43 Is a Component of Ubiquitin-Positive Tau-Negative Inclusions in Frontotemporal Lobar Degeneration and Amyotrophic Lateral Sclerosis. Biochem. Biophysical Res. Commun. 351, 602-611. doi:10.1016/j.bbrc.2006. 10.093

Asakawa, K., Handa, H., and Kawakami, K. (2020). Optogenetic Modulation of TDP-43 Oligomerization Accelerates ALS-Related Pathologies in the Spinal Motor Neurons. Nat. Commun. 11, 1004. doi:10.1038/s41467-020-14815-x

Ashe, M. P., De Long, S. K., and Sachs, A. B. (2000). Glucose Depletion Rapidly Inhibits Translation Initiation in Yeast. $M B o C$ 11, 833-848. doi:10.1091/mbc. 11.3.833

Aulas, A., Stabile, S., and Vande Velde, C. (2012). Endogenous TDP-43, but Not FUS, Contributes to Stress Granule Assembly via G3BP. Mol. Neurodegeneration 7, 54. doi:10.1186/1750-1326-7-54

Austin, J. A., Wright, G. S. A., Watanabe, S., Grossmann, J. G., Antonyuk, S. V., Yamanaka, K., et al. (2014). Disease Causing Mutants of TDP-43 Nucleic Acid Binding Domains Are Resistant to Aggregation and Have Increased Stability and Half-Life. Proc. Natl. Acad. Sci. 111, 4309-4314. doi:10.1073/pnas.1317317111 cellular response to aggregates, intense research needs to focus on the organelles, particularly lysosomes and autophagy system. Many fALS cases are associated with genes involved in the function of lysosomes, and impaired lysosome trafficking has been reported in ALS post-mortem tissue, as reviewed in Root et al. (2021). Hence, a cell-specific view that will focus both on the protein localization and the changes in concentrations, as well as the intracellular trafficking, promises to give necessary insights into the cellular pathophysiology of ALS.

\section{AUTHOR CONTRIBUTIONS}

$\mathrm{KM}, \mathrm{BR}, \mathrm{PA}, \mathrm{DB}$ and $\mathrm{DM}$ contributed to the conception, literature mining, design, and writing of the manuscript. All authors read and approved the final manuscript for submission.

\section{FUNDING}

The coopearation between KM, BR, PA, DB and DM is supported by the German Academic Exchange Service (DAAD PPE 2021/ 2022 to DM) and the Ministry of Education, Science and Technological Development of Republic of Serbia bilateral project with Federal Republic of Germany (2021/2022 to DB; Contract No. 451-03-9/2021-14/200178).

Banani, S. F., Lee, H. O., Hyman, A. A., and Rosen, M. K. (2017). Biomolecular Condensates: Organizers of Cellular Biochemistry. Nat. Rev. Mol. Cel Biol. 18, 285-298. doi:10.1038/nrm.2017.7

Banerjee, P. R., Milin, A. N., Moosa, M. M., Paulo, L., Deniz, A. A., Biology, C., et al. (2018). Reentrant Phase Transition Drives Dynamic Substructure Formation in Ribonucleoprotein Droplets. Angew. Chem. Int. Ed. Engl. 56, 11354-11359. doi:10.1002/anie.201703191

Baradaran-Heravi, Y., Van Broeckhoven, C., and van der Zee, J. (2020). Stress Granule Mediated Protein Aggregation and Underlying Gene Defects in the FTD-ALS Spectrum. Neurobiol. Dis. 134, 104639. doi:10.1016/j.nbd.2019. 104639

Barmada, S. J., and Finkbeiner, S. (2010). Pathogenic TARDBP Mutations in Amyotrophic Lateral Sclerosis and Frontotemporal Dementia: DiseaseAssociated Pathways. Rev. Neurosci. 21, 251-272. doi:10.1515/revneuro.2010. 21.4.251

Bäumer, D., Parkinson, N., and Talbot, K. (2009). TARDBP in Amyotrophic Lateral Sclerosis: Identification of a Novel Variant but Absence of Copy Number Variation. J. Neurol. Neurosurg. Psychiatry 80, 1283-1285. doi:10. 1136/jnnp.2008.166512

Beijer, D., Kim, H. J., Guo, L., O’Donovan, K., Mademan, I., Deconinck, T., et al. (2021). Characterization of HNRNPA1 Mutations Defines Diversity in Pathogenic Mechanisms and Clinical Presentation. JCI Insight 6, e148363. doi:10.1172/jci.insight.148363

Belzil, V. V., Valdmanis, P. N., Dion, P. A., Daoud, H., Kabashi, E., Noreau, A., et al (2009). Mutations in FUS Cause FALS and SALS in French and French Canadian Populations. Neurology 73, 1176-1179. doi:10.1212/WNL. 0b013e3181bbfeef

Bentmann, E., Neumann, M., Tahirovic, S., Rodde, R., Dormann, D., and Haass, C. (2012). Requirements for Stress Granule Recruitment of Fused in Sarcoma (FUS) and TAR DNA-Binding Protein of 43 kDa (TDP-43). J. Biol. Chem. 287, 23079-23094. doi:10.1074/jbc.M111.328757

Besse, F., and Ephrussi, A. (2008). Translational Control of Localized mRNAs: Restricting Protein Synthesis in Space and Time. Nat. Rev. Mol. Cel Biol. 9, 971-980. doi: $10.1038 / \mathrm{nrm} 2548$ 
Bilican, B., Serio, A., Barmada, S. J., Nishimura, A. L., Sullivan, G. J., Carrasco, M., et al. (2012). Mutant Induced Pluripotent Stem Cell Lines Recapitulate Aspects of TDP-43 Proteinopathies and Reveal Cell-specific Vulnerability. Proc. Natl. Acad. Sci. 109, 5803-5808. doi:10.1073/pnas.1202922109

Blokhuis, A. M., Groen, E. J. N., Koppers, M., van den Berg, L. H., and Pasterkamp, R. J. (2013). Protein Aggregation in Amyotrophic Lateral Sclerosis. Acta Neuropathol. 125, 777-794. doi:10.1007/s00401-013-1125-6

Blokhuis, A. M., Koppers, M., Groen, E. J. N., van den Heuvel, D. M. A., Dini Modigliani, S., Anink, J. J., et al. (2016). Comparative Interactomics Analysis of Different ALS-Associated Proteins Identifies Converging Molecular Pathways. Acta Neuropathol. 132, 175-196. doi:10.1007/s00401-016-1575-8

Bodansky, A., Kim, J. M. H., Tempest, L., Velagapudi, A., Libby, R., and Ravits, J. (2010). TDP-43 and Ubiquitinated Cytoplasmic Aggregates in Sporadic ALS Are Low Frequency and Widely Distributed in the Lower Motor Neuron Columns Independent of Disease Spread. Amyotroph. Lateral Scler. 11, 321-327. doi:10.3109/17482961003602363

Boeynaems, S., Bogaert, E., Kovacs, D., Konijnenberg, A., Timmerman, E., Volkov, A., et al. (2017). Phase Separation of C9orf72 Dipeptide Repeats Perturbs Stress Granule Dynamics. Mol. Cel 65, 1044-1055.e5. doi:10.1016/j.molcel.2017. 02.013

Bosco, D. A., Lemay, N., Ko, H. K., Zhou, H., Burke, C., Kwiatkowski, T. J., et al. (2010). Mutant FUS Proteins that Cause Amyotrophic Lateral Sclerosis Incorporate into Stress Granules. Hum. Mol. Genet. 19, 4160-4175. doi:10. 1093/hmg/ddq335

Brangwynne, C. P. (2013). Phase Transitions and Size Scaling of Membrane-Less Organelles. J. Cel Biol. 203, 875-881. doi:10.1083/jcb.201308087

Brettschneider, J., Del Tredici, K., Toledo, J. B., Robinson, J. L., Irwin, D. J., Grossman, M., et al. (2013). Stages of pTDP-43 Pathology in Amyotrophic Lateral Sclerosis. Ann. Neurol. 74, 20-38. doi:10.1002/ana.23937

Brown, R. H., and Al-Chalabi, A. (2017). Amyotrophic Lateral Sclerosis. N. Engl. J. Med. 377, 162-172. doi:10.1056/NEJMra1603471

Buchan, J. R., Kolaitis, R.-M., Taylor, J. P., and Parker, R. (2013). Eukaryotic Stress Granules Are Cleared by Autophagy and Cdc48/VCP Function. Cell 153, 1461-1474. doi:10.1016/j.cell.2013.05.037

Buchan, J. R., and Parker, R. (2009). Eukaryotic Stress Granules: The Ins and Outs of Translation. Mol. Cel 36, 932-941. doi:10.1016/j.molcel.2009.11.020

Buratti, E., and Baralle, F. E. (2008). Multiple Roles of TDP-43 in Gene Expression, Splicing Regulation, and Human Disease. Front. Biosci. 13, 867-878. doi:10. 2741/2727

Burkhardt, M. F., Martinez, F. J., Wright, S., Ramos, C., Volfson, D., Mason, M., et al. (2013). A Cellular Model for Sporadic ALS Using Patient-Derived Induced Pluripotent Stem Cells. Mol. Cell Neurosci. 56, 355-364. doi:10.1016/j.mcn. 2013.07.007

Chiang, H.-H., Andersen, P. M., Tysnes, O.-B., Gredal, O., Christensen, P. B., and Graff, C. (2012). Novel TARDBP Mutations in Nordic ALS Patients. J. Hum. Genet. 57, 316-319. doi:10.1038/jhg.2012.24

Chiò, A., Calvo, A., Moglia, C., Canosa, A., Brunetti, M., Barberis, M., et al. (2015). ATXN2 polyQ Intermediate Repeats Are a Modifier of ALS Survival. Neurology 84, 251-258. doi:10.1212/WNL.0000000000001159

Chou, C.-C., Zhang, Y., Umoh, M. E., Vaughan, S. W., Lorenzini, I., Liu, F., et al. (2018). TDP-43 Pathology Disrupts Nuclear Pore Complexes and Nucleocytoplasmic Transport in ALS/FTD. Nat. Neurosci. 21, 228-239. doi:10.1038/s41593-017-0047-3

Collins, M., Riascos, D., Kovalik, T., An, J., Krupa, K., Krupa, K., et al. (2012). The RNA-Binding Motif 45 (RBM45) Protein Accumulates in Inclusion Bodies in Amyotrophic Lateral Sclerosis (ALS) and Frontotemporal Lobar Degeneration with TDP-43 Inclusions (FTLD-TDP) Patients. Acta Neuropathol. 124, 717-732. doi:10.1007/s00401-012-1045-x

Conicella, A. E., Dignon, G. L., Zerze, G. H., Schmidt, H. B., D’Ordine, A. M., Kim, Y. C., et al. (2020). TDP-43 $a$-helical Structure Tunes Liquid-Liquid Phase Separation and Function. Proc. Natl. Acad. Sci. USA 117, 5883-5894. doi:10. 1073/pnas.1912055117

Conicella, A. E., Zerze, G. H., Mittal, J., and Fawzi, N. L. (2016). ALS Mutations Disrupt Phase Separation Mediated by a-Helical Structure in the TDP-43 Low-Complexity C-Terminal Domain. Structure 24, 1537-1549. doi:10.1016/j.str.2016.07.007

Corrado, L., Del Bo, R., Castellotti, B., Ratti, A., Cereda, C., Penco, S., et al. (2010). Mutations of FUS Gene in Sporadic Amyotrophic Lateral Sclerosis. J. Med. Genet. 47, 190-194. doi:10.1136/jmg.2009.071027
Corrado, L., Ratti, A., Gellera, C., Buratti, E., Castellotti, B., Carlomagno, Y., et al. (2009). High Frequency ofTARDBPgene Mutations in Italian Patients with Amyotrophic Lateral Sclerosis. Hum. Mutat. 30, 688-694. doi:10.1002/humu. 20950

Couthouis, J., Hart, M. P., Shorter, J., DeJesus-Hernandez, M., Erion, R., Oristano, R., et al. (2011). A Yeast Functional Screen Predicts New Candidate ALS Disease Genes. Proc. Natl. Acad. Sci. 108, 20881-20890. doi:10.1073/pnas.1109434108

Daoud, H., Valdmanis, P. N., Kabashi, E., Dion, P., Dupré, N., Camu, W., et al. (2009). Contribution of TARDBP Mutations to Sporadic Amyotrophic Lateral Sclerosis. J. Med. Genet. 46, 112-114. doi:10.1136/jmg.2008.062463

Decker, C. J., and Parker, R. (2012). P-bodies and Stress Granules: Possible Roles in the Control of Translation and mRNA Degradation. Cold Spring Harbor Perspect. Biol. 4, a012286. doi:10.1101/cshperspect.a012286

DeJesus-Hernandez, M., Kocerha, J., Finch, N., Crook, R., Baker, M., Desaro, P., et al. (2010). De Novo truncating FUS Gene Mutation as a Cause of Sporadic Amyotrophic Lateral Sclerosis. Hum. Mutat. 31, E1377-E1389. doi:10.1002/ humu. 21241

Deng, H., Gao, K., and Jankovic, J. (2014). The Role of FUS Gene Variants in Neurodegenerative Diseases. Nat. Rev. Neurol. 10, 337-348. doi:10.1038/ nrneurol.2014.78

Dewey, C. M., Cenik, B., Sephton, C. F., Johnson, B. A., Herz, J., and Yu, G. (2012). TDP-43 Aggregation in Neurodegeneration: Are Stress Granules the Key? Brain Res. 1462, 16-25. doi:10.1016/j.brainres.2012.02.032

Dormann, D., Madl, T., Valori, C. F., Bentmann, E., Tahirovic, S., Abou-Ajram, C., et al. (2012). Arginine Methylation Next to the PY-NLS Modulates Transportin Binding and Nuclear Import of FUS. EMBO J. 31, 4258-4275. doi:10.1038/ emboj.2012.261

Dormann, D., Rodde, R., Edbauer, D., Bentmann, E., Fischer, I., Hruscha, A., et al. (2010). ALS-associated Fused in Sarcoma (FUS) Mutations Disrupt Transportin-Mediated Nuclear Import. EMBO J. 29, 2841-2857. doi:10. 1038/emboj.2010.143

Egawa, N., Kitaoka, S., Tsukita, K., Naitoh, M., Takahashi, K., Yamamoto, T., et al. (2012). Drug Screening for ALS Using Patient-specific Induced Pluripotent Stem Cells. Sci. Transl. Med. 4, 145ra104. doi:10.1126/scitranslmed.3004052

Elbaum-Garfinkle, S., Kim, Y., Szczepaniak, K., Chen, C. C.-H., Eckmann, C. R., Myong, S., et al. (2015). The Disordered P Granule Protein LAF-1 Drives Phase Separation into Droplets with Tunable Viscosity and Dynamics. Proc. Natl. Acad. Sci. USA 112, 7189-7194. doi:10.1073/pnas.1504822112

Elden, A. C., Kim, H.-J., Hart, M. P., Chen-Plotkin, A. S., Johnson, B. S., Fang, X., et al. (2010). Ataxin-2 Intermediate-Length Polyglutamine Expansions Are Associated with Increased Risk for ALS. Nature 466, 1069-1075. doi:10.1038/ nature 09320

Fernandopulle, M. S., Lippincott-Schwartz, J., and Ward, M. E. (2021). RNA Transport and Local Translation in Neurodevelopmental and Neurodegenerative Disease. Nat. Neurosci. 24, 622-632. doi:10.1038/s41593020-00785-2

Forsberg, K., Graffmo, K., Pakkenberg, B., Weber, M., Nielsen, M., Marklund, S., et al. (2019). Misfolded SOD1 Inclusions in Patients with Mutations in C9orf72 and Other ALS/FTD-associated Genes. J. Neurol. Neurosurg. Psychiatry 90, 861-869. doi:10.1136/jnnp-2018-319386

Fujimori, K., Ishikawa, M., Otomo, A., Atsuta, N., Nakamura, R., Akiyama, T., et al. (2018). Modeling Sporadic ALS in iPSC-Derived Motor Neurons Identifies a Potential Therapeutic Agent. Nat. Med. 24, 1579-1589. doi:10.1038/s41591018-0140-5

Gal, J., Kuang, L., Barnett, K. R., Zhu, B. Z., Shissler, S. C., Korotkov, K. V., et al. (2016). ALS Mutant SOD1 Interacts with G3BP1 and Affects Stress Granule Dynamics. Acta Neuropathol. 132, 563-576. doi:10.1007/s00401-016-1601-x

Gal, J., Zhang, J., Kwinter, D. M., Zhai, J., Jia, H., Jia, J., et al. (2011). Nuclear Localization Sequence of FUS and Induction of Stress Granules by ALS Mutants. Neurobiol. Aging 32, e27-2323. doi:10.1016/j.neurobiolaging.2010. 06.010

Ganassi, M., Mateju, D., Bigi, I., Mediani, L., Poser, I., Lee, H. O., et al. (2016). A Surveillance Function of the HSPB8-BAG3-HSP70 Chaperone Complex Ensures Stress Granule Integrity and Dynamism. Mol. Cel 63, 796-810. doi:10.1016/j.molcel.2016.07.021

Gilpin, K. M., Chang, L., and Monteiro, M. J. (2015). ALS-linked Mutations in Ubiquilin-2 or hnRNPA1 Reduce Interaction between Ubiquilin-2 and hnRNPA1. Hum. Mol. Genet. 24, 2565-2577. doi:10.1093/hmg/ddv020 
Gitcho, M. A., Baloh, R. H., Chakraverty, S., Mayo, K., Norton, J. B., Levitch, D., et al. (2008). TDP-43A315T Mutation in Familial Motor Neuron Disease. Ann. Neurol. 63, 535-538. doi:10.1002/ana.21344

Gopal, P. P., Nirschl, J. J., Klinman, E., and Holzbaur, E. L. F. (2017). Amyotrophic Lateral Sclerosis-Linked Mutations Increase the Viscosity of Liquid-like TDP43 RNP Granules in Neurons. Proc. Natl. Acad. Sci. USA 114, E2466-E2475. doi:10.1073/pnas.1614462114

Groen, E. J. N., van Es, M. A., Spliet, W. G. M., van Engelen-Lee, J., de Visser, M., Wokke, J. H. J., et al. (2010). FUS Mutations in Familial Amyotrophic Lateral Sclerosis in the Netherlands. Arch. Neurol. 67, 224-230. doi:10.1001/ archneurol.2009.329

Guo, L., Kim, H. J., Wang, H., Monaghan, J., Freyermuth, F., Sung, J. C., et al. (2018). Nuclear-Import Receptors Reverse Aberrant Phase Transitions of RNABinding Proteins with Prion-like Domains. Cell 173, 677-692.e20. doi:10.1016/ j.cell.2018.03.002

Hackman, P., Sarparanta, J., Lehtinen, S., Vihola, A., Evilä, A., Jonson, P. H., et al. (2013). Welander Distal Myopathy Is Caused by a Mutation in the RNABinding Protein TIA1. Ann. Neurol. 73, 500-509. doi:10.1002/ana.23831

Han, T. W., Kato, M., Xie, S., Wu, L. C., Mirzaei, H., Pei, J., et al. (2012). Cell-free Formation of RNA Granules: Bound RNAs Identify Features and Components of Cellular Assemblies. Cell 149, 768-779. doi:10.1016/j.cell.2012.04.016

Hasegawa, M., Arai, T., Nonaka, T., Kametani, F., Yoshida, M., Hashizume, Y., et al. (2008). Phosphorylated TDP-43 in Frontotemporal Lobar Degeneration and Amyotrophic Lateral Sclerosis. Ann. Neurol. 64, 60-70. doi:10.1002/ana. 21425

Hoffmann, C., Sansevrino, R., Morabito, G., Logan, C., Vabulas, R. M., Ulusoy, A., et al. (2021). Synapsin Condensates Recruit Alpha-Synuclein. J. Mol. Biol. 433, 166961. doi:10.1016/j.jmb.2021.166961

Hofmann, S., Kedersha, N., Anderson, P., and Ivanov, P. (2021). Molecular Mechanisms of Stress Granule Assembly and Disassembly. Biochim. Biophys. Acta (Bba) - Mol. Cel Res. 1868, 118876. doi:10.1016/j.bbamcr.2020.118876

Hofweber, M., and Dormann, D. (2019). Friend or foe-Post-translational Modifications as Regulators of Phase Separation and RNP Granule Dynamics. J. Biol. Chem. 294, 7137-7150. doi:10.1074/jbc.TM118.001189

Hofweber, M., Hutten, S., Bourgeois, B., Spreitzer, E., Niedner-Boblenz, A., Schifferer, M., et al. (2018). Phase Separation of FUS Is Suppressed by its Nuclear Import Receptor and Arginine Methylation. Cell 173, 706-719.e13. doi:10.1016/j.cell.2018.03.004

Hutten, S., Usluer, S., Bourgeois, B., Simonetti, F., Odeh, H. M., Fare, C. M., et al. (2020). Nuclear Import Receptors Directly Bind to Arginine-Rich Dipeptide Repeat Proteins and Suppress Their Pathological Interactions. Cel Rep. 33, 108538. doi:10.1016/j.celrep.2020.108538

Jain, A., and Vale, R. D. (2017). RNA Phase Transitions in Repeat Expansion Disorders. Nature 546, 243-247. doi:10.1038/nature22386

Jain, S., Wheeler, J. R., Walters, R. W., Agrawal, A., Barsic, A., and Parker, R. (2016). ATPase-Modulated Stress Granules Contain a Diverse Proteome and Substructure. Cell 164, 487-498. doi:10.1016/j.cell.2015.12.038

Johnson, B. S., Snead, D., Lee, J. J., McCaffery, J. M., Shorter, J., and Gitler, A. D. (2009). TDP-43 Is Intrinsically Aggregation-Prone, and Amyotrophic Lateral Sclerosis-Linked Mutations Accelerate Aggregation and Increase Toxicity. J. Biol. Chem. 284, 20329-20339. doi:10.1074/jbc.M109.010264

Jonsson, P. A., Bergemalm, D., Andersen, P. M., Gredal, O., Brännström, T., and Marklund, S. L. (2008). Inclusions of Amyotrophic Lateral Sclerosis-Linked Superoxide Dismutase in Ventral Horns, Liver, and Kidney. Ann. Neurol. 63, 671-675. doi:10.1002/ana.21356

Jonsson, P. A., Ernhill, K., Andersen, P. M., Bergemalm, D., Brännström, T., Gredal, O., et al. (2004). Minute Quantities of Misfolded Mutant Superoxide Dismutase-1 Cause Amyotrophic Lateral Sclerosis. Brain 127, 73-88. doi:10. 1093/brain/awh005

Kabashi, E., Valdmanis, P. N., Dion, P., Spiegelman, D., McConkey, B. J., Velde, C. V., et al. (2008). TARDBP Mutations in Individuals with Sporadic and Familial Amyotrophic Lateral Sclerosis. Nat. Genet. 40, 572-574. doi:10.1038/ng.132

Kamada, M., Maruyama, H., Tanaka, E., Morino, H., Wate, R., Ito, H., et al. (2009). Screening for TARDBP Mutations in Japanese Familial Amyotrophic Lateral Sclerosis. J. Neurol. Sci. 284, 69-71. doi:10.1016/j.jns.2009.04.017

Kato, M., Han, T. W., Xie, S., Shi, K., Du, X., Wu, L. C., et al. (2012). Cell-free Formation of RNA Granules: Low Complexity Sequence Domains Form
Dynamic Fibers within Hydrogels. Cell 149, 753-767. doi:10.1016/j.cell.2012. 04.017

Kawaguchi, Y., Kovacs, J. J., McLaurin, A., Vance, J. M., Ito, A., and Yao, T.-P. (2003). The Deacetylase HDAC6 Regulates Aggresome Formation and Cell Viability in Response to Misfolded Protein Stress. Cell 115, 727-738. doi:10. 1016/s0092-8674(03)00939-5

Kedersha, N., Ivanov, P., and Anderson, P. (2013). Stress Granules and Cell Signaling: More Than Just a Passing Phase? Trends Biochem. Sci. 38, 494-506. doi:10.1016/j.tibs.2013.07.004

Kedersha, N., Panas, M. D., Achorn, C. A., Lyons, S., Tisdale, S., Hickman, T., et al. (2016). G3BP-Caprin1-USP10 Complexes Mediate Stress Granule Condensation and Associate with 40S Subunits. J. Cel Biol. 212, 845. doi:10. 1083/jcb.201508028

Kedersha, N., Stoecklin, G., Ayodele, M., Yacono, P., Lykke-Andersen, J., Fritzler, M. J., et al. (2005). Stress Granules and Processing Bodies Are Dynamically Linked Sites of mRNP Remodeling. J. Cel Biol. 169, 871-884. doi:10.1083/jcb. 200502088

Khalfallah, Y., Kuta, R., Grasmuck, C., Prat, A., Durham, H. D., and Vande Velde, C. (2018). TDP-43 Regulation of Stress Granule Dynamics in Neurodegenerative Disease-Relevant Cell Types. Sci. Rep. 8, 7551. doi:10. 1038/s41598-018-25767-0

Kim, G., Gautier, O., Tassoni-Tsuchida, E., Ma, X. R., and Gitler, A. D. (2020). ALS Genetics: Gains, Losses, and Implications for Future Therapies. Neuron 108, 822-842. doi:10.1016/j.neuron.2020.08.022

Kim, H. J., Kim, N. C., Wang, Y.-D., Scarborough, E. A., Moore, J., Diaz, Z., et al. (2013). Mutations in Prion-like Domains in hnRNPA2B1 and hnRNPA1 Cause Multisystem Proteinopathy and ALS. Nature 495, 467-473. doi:10.1038/ nature11922

Kim, W., Kim, D.-Y., and Lee, K.-H. (2021). Rna-binding Proteins and the Complex Pathophysiology of Als. Int. J. Mol. Sci. 22, 2598. doi:10.3390/ ijms 22052598

Kirby, J., Goodall, E. F., Smith, W., Highley, J. R., Masanzu, R., Hartley, J. A., et al. (2010). Broad Clinical Phenotypes Associated with TAR-DNA Binding Protein (TARDBP) Mutations in Amyotrophic Lateral Sclerosis. Neurogenetics 11, 217-225. doi:10.1007/s10048-009-0218-9

Kwiatkowski, T. J., Bosco, D. A., LeClerc, A. L., Tamrazian, E., Vanderburg, C. R., Russ, C., et al. (2009). Mutations in the FUS/TLS Gene on Chromosome 16 Cause Familial Amyotrophic Lateral Sclerosis. Science 323, 1205-1208. doi:10. 1126/science.1166066

Kwon, M.-J., Baek, W., Ki, C.-S., Kim, H. Y., Koh, S.-H., Kim, J.-W., et al. (2012). Screening of the SOD1, FUS, TARDBP, ANG, and OPTN Mutations in Korean Patients with Familial and Sporadic ALS. Neurobiol. Aging 33, e17-1017. doi:10. 1016/j.neurobiolaging.2011.12.003

Lattante, S., Conte, A., Zollino, M., Luigetti, M., Del Grande, A., Marangi, G., et al (2012). Contribution of Major Amyotrophic Lateral Sclerosis Genes to the Etiology of Sporadic Disease. Neurology 79, 66-72. doi:10.1212/WNL. ob013e31825dceca

Lee, B. J., Cansizoglu, A. E., Süel, K. E., Louis, T. H., Zhang, Z., and Chook, Y. M. (2006). Rules for Nuclear Localization Sequence Recognition by Karyopherin $\beta 2$. Cell 126, 543-558. doi:10.1016/j.cell.2006.05.049

Lee, D.-Y., Jeon, G. S., and Sung, J.-J. (2020). ALS-linked Mutant SOD1 Associates with TIA-1 and Alters Stress Granule Dynamics. Neurochem. Res. 45, 2884-2893. doi:10.1007/s11064-020-03137-5

Leigh, P. N., Whitwell, H., Garofalo, O., Buller, J., Swash, M., Martin, J. E., et al. (1991). Ubiquitin-immunoreactive Intraneuronal Inclusions in Amyotrophic Lateral Sclerosis. Brain 114, 775-788. doi:10.1093/brain/114.2.775

Lemmens, R., Race, V., Hersmus, N., Matthijs, G., Van Den Bosch, L., Van Damme, P., et al. (2009). TDP-43 M311V Mutation in Familial Amyotrophic Lateral Sclerosis. J. Neurol. Neurosurg. Psychiatry 80, 354-355. doi:10.1136/jnnp.2008. 157677

Li, Y. R., King, O. D., Shorter, J., and Gitler, A. D. (2013). Stress Granules as Crucibles of ALS Pathogenesis. J. Cel Biol. 201, 361-372. doi:10.1083/jcb. 201302044

Liao, Y.-C., Fernandopulle, M. S., Wang, G., Choi, H., Hao, L., Drerup, C. M., et al. (2019). RNA Granules Hitchhike on Lysosomes for Long-Distance Transport, Using Annexin A11 as a Molecular Tether. Cell 179, 147-164. doi:10.1016/j.cell. 2019.08.050 
Lin, Y., Protter, D. S. W., Rosen, M. K., and Parker, R. (2015). Formation and Maturation of Phase-Separated Liquid Droplets by RNA-Binding Proteins. Mol. Cel 60, 208-219. doi:10.1016/j.molcel.2015.08.018

Ling, S.-C., Albuquerque, C. P., Han, J. S., Lagier-Tourenne, C., Tokunaga, S., Zhou, H., et al. (2010). ALS-associated Mutations in TDP-43 Increase its Stability and Promote TDP-43 Complexes with FUS/TLS. Proc. Natl. Acad. Sci. 107, 13318-13323. doi:10.1073/pnas.1008227107

Ling, S.-C., Dastidar, S. G., Tokunaga, S., Ho, W. Y., Lim, K., Ilieva, H., et al. (2019). Overriding FUS Autoregulation in Mice Triggers Gain-Of-Toxic Dysfunctions in RNA Metabolism and Autophagy-Lysosome axis. Elife 8, e40811. doi:10. 7554/eLife.40811

Liscic, R. M., Alberici, A., Cairns, N. J., Romano, M., and Buratti, E. (2020). From Basic Research to the Clinic: Innovative Therapies for ALS and FTD in the Pipeline. Mol. Neurodegeneration 15, 31. doi:10.1186/s13024-020-00373-9

Liu, Q., Shu, S., Wang, R. R., Liu, F., Cui, B., Guo, X. N., et al. (2016). Whole-exome Sequencing Identifies a Missense Mutation in hnRNPA1 in a Family with Flail Arm ALS. Neurology 87, 1763-1769. doi:10.1212/WNL.0000000000003256

Liu, X., Wu, C., He, J., Zhang, N., and Fan, D. (2019). Two Rare Variants of the ANXA11 Gene Identified in Chinese Patients with Amyotrophic Lateral Sclerosis. Neurobiol. Aging 74, e9-235. doi:10.1016/j.neurobiolaging.2018. 09.020

Longinetti, E., and Fang, F. (2019). Epidemiology of Amyotrophic Lateral Sclerosis: An Update of Recent Literature. Curr. Opin. Neurol. 32, 771-776. doi:10.1097/ WCO.0000000000000730

Lu, S., Hu, J., Aladesuyi, B., Goginashvili, A., Vazquez-Sanchez, S., Diedrich, J., et al. (2021). Heat Shock Chaperone HSPB1 Regulates Cytoplasmic TDP-43 Phase Separation and Liquid-To-Gel Transition. bioRxiv, 2021.10.14.464447. doi:10. 1101/2021.10.14.464447

Mackenzie, I. R. A., Bigio, E. H., Ince, P. G., Geser, F., Neumann, M., Cairns, N. J., et al. (2007). Pathological TDP-43 Distinguishes Sporadic Amyotrophic Lateral Sclerosis from Amyotrophic Lateral Sclerosis withSOD1 Mutations. Ann. Neurol. 61, 427-434. doi:10.1002/ana.21147

Mackenzie, I. R., Nicholson, A. M., Sarkar, M., Messing, J., Purice, M. D., Pottier, C., et al. (2017). TIA1 Mutations in Amyotrophic Lateral Sclerosis and Frontotemporal Dementia Promote Phase Separation and Alter Stress Granule Dynamics. Neuron 95, 808-816.e9. doi:10.1016/j.neuron.2017.07.025

Maharana, S., Wang, J., Papadopoulos, D. K., Richter, D., Pozniakovsky, A., Poser, I., et al. (2018). RNA Buffers the Phase Separation Behavior of Prion-like RNA Binding Proteins. Science 360, 918-921. doi:10.1126/science.aar7366.RNA

Malik, R., and Wiedau, M. (2020). Therapeutic Approaches Targeting Protein Aggregation in Amyotrophic Lateral Sclerosis. Front. Mol. Neurosci. 13, 98. doi:10.3389/fnmol.2020.00098

Marmor-Kollet, H., Siany, A., Kedersha, N., Knafo, N., Rivkin, N., Danino, Y. M., et al. (2020). Spatiotemporal Proteomic Analysis of Stress Granule Disassembly Using APEX Reveals Regulation by SUMOylation and Links to ALS Pathogenesis. Mol. Cel 80, 876-891.e6. doi:10.1016/j.molcel.2020.10.032

Mateju, D., Franzmann, T. M., Patel, A., Kopach, A., Boczek, E. E., Maharana, S., et al. (2017). An Aberrant Phase Transition of Stress Granules Triggered by Misfolded Protein and Prevented by Chaperone Function. EMBO J. 36, 1669-1687. doi:10.15252/embj.201695957

Mattis, V. B., and Svendsen, C. N. (2011). Induced Pluripotent Stem Cells: A New Revolution for Clinical Neurology? Lancet Neurol. 10, 383-394. doi:10.1016/ S1474-4422(11)70022-9

McGurk, L., Gomes, E., Guo, L., Mojsilovic-Petrovic, J., Tran, V., Kalb, R. G., et al. (2018). Poly(ADP-Ribose) Prevents Pathological Phase Separation of TDP-43 by Promoting Liquid Demixing and Stress Granule Localization. Mol. Cel 71, 703-717.e9. doi:10.1016/j.molcel.2018.07.002

Mejzini, R., Flynn, L. L., Pitout, I. L., Fletcher, S., Wilton, S. D., and Akkari, P. A. (2019). ALS Genetics, Mechanisms, and Therapeutics: Where Are We Now? Front. Neurosci. 13, 1310. doi:10.3389/fnins.2019.01310

Merner, N. D., Girard, S. L., Catoire, H., Bourassa, C. V., Belzil, V. V., Rivière, J.-B., et al. (2012). Exome Sequencing Identifies FUS Mutations as a Cause of Essential Tremor. Am. J. Hum. Genet. 91, 313-319. doi:10.1016/j.ajhg.2012.07.002

Milovanovic, D., Wu, Y., Bian, X., and De Camilli, P. (2018). A Liquid Phase of Synapsin and Lipid Vesicles. Science 361, 604-607. doi:10.1126/science.aat5671

Mittag, T., and Parker, R. (2018). Multiple Modes of Protein-Protein Interactions Promote RNP Granule Assembly. J. Mol. Biol. 430, 4636-4649. doi:10.1016/j. jmb.2018.08.005
Molliex, A., Temirov, J., Lee, J., Coughlin, M., Kanagaraj, A. P., Kim, H. J., et al. (2015). Phase Separation by Low Complexity Domains Promotes Stress Granule Assembly and Drives Pathological Fibrillization. Cell 163, 123-133. doi:10.1016/j.cell.2015.09.015

Monahan, Z., Ryan, V. H., Janke, A. M., Burke, K. A., Rhoads, S. N., Zerze, G. H., et al. (2017). Phosphorylation of the FUS Low-complexity Domain Disrupts Phase Separation, Aggregation, and Toxicity. EMBO J. 36, 2951-2967. doi:10. 15252/embj.201696394

Moujalled, D., and White, A. R. (2016). Advances in the Development of DiseaseModifying Treatments for Amyotrophic Lateral Sclerosis. CNS Drugs 30, 227-243. doi:10.1007/s40263-016-0317-8

Murray, D. T., Kato, M., Lin, Y., Thurber, K. R., Hung, I., McKnight, S. L., et al. (2017). Structure of FUS Protein Fibrils and its Relevance to Self-Assembly and Phase Separation of Low-Complexity Domains. Cell 171, 615-627. doi:10.1016/ j.cell.2017.08.048

Nahm, M., Lim, S. M., Kim, Y.-E., Park, J., Noh, M.-Y., Lee, S., et al. (2020). ANXA11 Mutations in ALS Cause Dysregulation of Calcium Homeostasis and Stress Granule Dynamics. Sci. Transl. Med. 12. doi:10.1126/scitranslmed. aax3993

Naruse, H., Ishiura, H., Mitsui, J., Date, H., Takahashi, Y., Matsukawa, T., et al. (2018). Molecular Epidemiological Study of Familial Amyotrophic Lateral Sclerosis in Japanese Population by Whole-Exome Sequencing and Identification of Novel HNRNPA1 Mutation. Neurobiol. Aging 61, e9-255. doi:10.1016/j.neurobiolaging.2017.08.030

Neumann, M., Kwong, L. K., Lee, E. B., Kremmer, E., Flatley, A., Xu, Y., et al. (2009). Phosphorylation of S409/410 of TDP-43 Is a Consistent Feature in All Sporadic and Familial Forms of TDP-43 Proteinopathies. Acta Neuropathol. 117, 137-149. doi:10.1007/s00401-008-0477-9

Neumann, M., Sampathu, D. M., Kwong, L. K., Truax, A. C., Micsenyi, M. C., Chou, T. T., et al. (2006). Ubiquitinated TDP-43 in Frontotemporal Lobar Degeneration and Amyotrophic Lateral Sclerosis. Science 314, 130-133. doi:10. $1126 /$ science. 1134108

Niaki, A. G., Sarkar, J., Cai, X., Rhine, K., Vidaurre, V., Guy, B., et al. (2020). Loss of Dynamic RNA Interaction and Aberrant Phase Separation Induced by Two Distinct Types of ALS/FTD-Linked FUS Mutations. Mol. Cel 77, 82-94.e4. doi:10.1016/j.molcel.2019.09.022

Niu, C., Zhang, J., Gao, F., Yang, L., Jia, M., Zhu, H., et al. (2012). FUS-NLS/ Transportin 1 Complex Structure Provides Insights into the Nuclear Targeting Mechanism of FUS and the Implications in ALS. PLoS One 7, e47056. doi:10. 1371/journal.pone.0047056

Nomura, T., Watanabe, S., Kaneko, K., Yamanaka, K., Nukina, N., and Furukawa, Y. (2014). Intranuclear Aggregation of Mutant FUS/TLS as a Molecular Pathomechanism of Amyotrophic Lateral Sclerosis. J. Biol. Chem. 289, 1192-1202. doi:10.1074/jbc.M113.516492

Nonaka, T., Kametani, F., Arai, T., Akiyama, H., and Hasegawa, M. (2009). Truncation and Pathogenic Mutations Facilitate the Formation of Intracellular Aggregates of TDP-43. Hum. Mol. Genet. 18, 3353-3364. doi: $10.1093 / \mathrm{hmg} / \mathrm{ddp} 275$

Nonhoff, U., Ralser, M., Welzel, F., Piccini, I., Balzereit, D., Yaspo, M.-L., et al. (2007). Ataxin-2 Interacts with the DEAD/H-box RNA Helicase DDX6 and Interferes with P-Bodies and Stress Granules. MBoC 18, 1385-1396. doi:10. 1091/mbc.e06-12-1120

Nussbacher, J. K., Batra, R., Lagier-Tourenne, C., and Yeo, G. W. (2015). RNAbinding Proteins in Neurodegeneration: Seq and You Shall Receive. Trends Neurosciences 38, 226-236. doi:10.1016/j.tins.2015.02.003

Nussbacher, J. K., Tabet, R., Yeo, G. W., and Lagier-Tourenne, C. (2019). Disruption of RNA Metabolism in Neurological Diseases and Emerging Therapeutic Interventions. Neuron 102, 294-320. doi:10.1016/j.neuron.2019. 03.014

Pakravan, D., Orlando, G., Bercier, V., and Van Den Bosch, L. (2021). Role and Therapeutic Potential of Liquid-Liquid Phase Separation in Amyotrophic Lateral Sclerosis. J. Mol. Cel Biol. 13, 15-28. doi:10.1093/jmcb/mjaa049

Panas, M. D., Ivanov, P., and Anderson, P. (2016). Mechanistic Insights into Mammalian Stress Granule Dynamics. J. Cel Biol. 215, 313-323. doi:10.1083/ jcb.201609081

Patel, A., Lee, H. O., Jawerth, L., Maharana, S., Jahnel, M., Hein, M. Y., et al. (2015). A Liquid-To-Solid Phase Transition of the ALS Protein FUS Accelerated by Disease Mutation. Cell 162, 1066-1077. doi:10.1016/j.cell.2015.07.047 
Picher-Martel, V., Valdmanis, P. N., Gould, P. V., Julien, J.-P., and Dupré, N. (2016). From Animal Models to Human Disease: A Genetic Approach for Personalized Medicine in ALS. Acta Neuropathol. Commun. 4, 1-29. doi:10. 1186/s40478-016-0340-5

Prasad, A., Bharathi, V., Sivalingam, V., Girdhar, A., and Patel, B. K. (2019). Molecular Mechanisms of TDP-43 Misfolding and Pathology in Amyotrophic Lateral Sclerosis. Front. Mol. Neurosci. 12, 1-36. doi:10.3389/fnmol.2019.00025

Rademakers, R., Stewart, H., Dejesus-Hernandez, M., Krieger, C., Graff-Radford, N., Fabros, M., et al. (2010). Fusgene Mutations in Familial and Sporadic Amyotrophic Lateral Sclerosis. Muscle Nerve 42, 170-176. doi:10.1002/mus. 21665

Rajpurohit, C. S., Kumar, V., Cheffer, A., Oliveira, D., Ulrich, H., Okamoto, O. K., et al. (2020). Mechanistic Insights of Astrocyte-Mediated Hyperactive Autophagy and Loss of Motor Neuron Function in SOD1L39R Linked Amyotrophic Lateral Sclerosis. Mol. Neurobiol. 57, 4117-4133. doi:10.1007/ s12035-020-02006-0

Ramaswami, M., Taylor, J. P., and Parker, R. (2013). Altered Ribostasis: RNAProtein Granules in Degenerative Disorders. Cell 154, 727-736. doi:10.1016/j. cell.2013.07.038

Rebane, A. A., Ziltener, P., LaMonica, L. C., Bauer, A. H., Zheng, H., LópezMontero, I., et al. (2020). Liquid-liquid Phase Separation of the Golgi Matrix Protein GM130. FEBS Lett. 594, 1132-1144. doi:10.1002/1873-3468.13715

Root, J., Merino, P., Nuckols, A., Johnson, M., and Kukar, T. (2021). Lysosome Dysfunction as a Cause of Neurodegenerative Diseases: Lessons from Frontotemporal Dementia and Amyotrophic Lateral Sclerosis. Neurobiol. Dis. 154, 105360. doi:10.1016/j.nbd.2021.105360

Rosen, D. R., Siddique, T., Patterson, D., Figlewicz, D. A., Sapp, P., Hentati, A., et al. (1993). Mutations in Cu/Zn Superoxide Dismutase Gene Are Associated with Familial Amyotrophic Lateral Sclerosis. Nature 362, 59-62. doi:10.1038/ 362059a0

Rulten, S. L., Rotheray, A., Green, R. L., Grundy, G. J., Moore, D. A. Q., GómezHerreros, F., et al. (2014). PARP-1 Dependent Recruitment of the Amyotrophic Lateral Sclerosis-Associated Protein FUS/TLS to Sites of Oxidative DNA Damage. Nucleic Acids Res. 42, 307-314. doi:10.1093/nar/gkt835

Sanchez de Groot, N., Armaos, A., Graña-Montes, R., Alriquet, M., Calloni, G., Vabulas, R. M., et al. (2019). RNA Structure Drives Interaction with Proteins. Nat. Commun. 10, 3246. doi:10.1038/s41467-019-10923-5

Scaramuzzino, C., Monaghan, J., Milioto, C., Lanson, N. A., Jr, Maltare, A., Aggarwal, T., et al. (2013). Protein Arginine Methyltransferase 1 and 8 Interact with FUS to Modify its Sub-cellular Distribution and Toxicity In Vitro and In Vivo. PLoS One 8, e61576. doi:10.1371/journal.pone.0061576

Schisa, J. A., and Elaswad, M. T. (2021). An Emerging Role for Post-translational Modifications in Regulating RNP Condensates in the Germ Line. Front. Mol. Biosci. 8, 1-9. doi:10.3389/fmolb.2021.658020

Schuster, B. S., Dignon, G. L., Tang, W. S., Kelley, F. M., Ranganath, A. K., Jahnke, C. N., et al. (2020). Identifying Sequence Perturbations to an Intrinsically Disordered Protein that Determine its Phase-Separation Behavior. Proc. Natl. Acad. Sci. USA 117, 11421-11431. doi:10.1073/pnas.2000223117

Serio, A., Bilican, B., Barmada, S. J., Ando, D. M., Zhao, C., Siller, R., et al. (2013). Astrocyte Pathology and the Absence of Non-cell Autonomy in an Induced Pluripotent Stem Cell Model of TDP-43 Proteinopathy. Proc. Natl. Acad. Sci. 110, 4697-4702. doi:10.1073/pnas.1300398110

Shaw, C., Morrice, J., and Gregory-Evans, C. (2018). Animal Models of Amyotrophic Lateral Sclerosis: A Comparison of Model Validity. Neural Regen. Res. 13, 2050. doi:10.4103/1673-5374.241445

Smith, B. N., Topp, S. D., Fallini, C., Shibata, H., Chen, H.-J., Troakes, C., et al. (2017). Mutations in the Vesicular Trafficking Protein Annexin A11 Are Associated with Amyotrophic Lateral Sclerosis. Sci. Transl. Med. 9, eaad9157. doi:10.1126/scitranslmed.aad9157

Spriggs, K. A., Bushell, M., and Willis, A. E. (2010). Translational Regulation of Gene Expression during Conditions of Cell Stress. Mol. Cel 40, 228-237. doi:10. 1016/j.molcel.2010.09.028

Sproviero, W., Shatunov, A., Stahl, D., Shoai, M., van Rheenen, W., Jones, A. R., et al. (2017). ATXN2 Trinucleotide Repeat Length Correlates with Risk of ALS. Neurobiol. Aging 51, e1-178. doi:10.1016/j.neurobiolaging.2016.11.010

Sreedharan, J., Blair, I. P., Tripathi, V. B., Hu, X., Vance, C., Rogelj, B., et al. (2008). TDP-43 Mutations in Familial and Sporadic Amyotrophic Lateral Sclerosis. Science 319, 1668-1672. doi:10.1126/science.1154584
Stamenković, S., Dučić, T., Stamenković, V., Kranz, A., and Andjus, P. R. (2017). Imaging of Glial Cell Morphology, SOD1 Distribution and Elemental Composition in the Brainstem and hippocampus of the ALS hSOD1G93A Rat. Neuroscience 357, 37-55. doi:10.1016/j.neuroscience. 2017.05.041

Sternburg, E. L., Gruijs da Silva, L. A., and Dormann, D. (2022). Post-translational Modifications on RNA-Binding Proteins: Accelerators, Brakes, or Passengers in Neurodegeneration? Trends Biochem. Sci. 47, 6-22. doi:10.1016/j.tibs.2021. 07.004

Suárez-Calvet, M., Neumann, M., Arzberger, T., Abou-Ajram, C., Funk, E., Hartmann, H., et al. (2016). Monomethylated and Unmethylated FUS Exhibit Increased Binding to Transportin and Distinguish FTLD-FUS from ALS-FUS. Acta Neuropathol. 131, 587-604. doi:10.1007/s00401-016-1544-2

Tan, C.-F., Eguchi, H., Tagawa, A., Onodera, O., Iwasaki, T., Tsujino, A., et al. (2007). TDP-43 Immunoreactivity in Neuronal Inclusions in Familial Amyotrophic Lateral Sclerosis with or without SOD1 Gene Mutation. Acta Neuropathol. 113, 535-542. doi:10.1007/s00401-007-0206-9

Taylor, J. P., Brown, R. H., and Cleveland, D. W. (2016). Decoding ALS: from Genes to Mechanism. Nature 539, 197-206. doi:10.1038/nature20413

Tian, S., Curnutte, H. A., and Trcek, T. (2020). RNA Granules: A View from the RNA Perspective. Molecules 25, 3130. doi:10.3390/molecules25143130

Ticozzi, N., LeClerc, A. L., van Blitterswijk, M., Keagle, P., McKenna-Yasek, D. M., Sapp, P. C., et al. (2011a). Mutational Analysis of TARDBP in Neurodegenerative Diseases. Neurobiol. Aging 32, 2096-2099. doi:10.1016/j. neurobiolaging.2009.11.018

Ticozzi, N., Silani, V., LeClerc, A. L., Keagle, P., Gellera, C., Ratti, A., et al. (2009). Analysis of FUS Gene Mutation in Familial Amyotrophic Lateral Sclerosis within an Italian Cohort. Neurology 73, 1180-1185. doi:10.1212/WNL. 0b013e3181bbff05

Ticozzi, N., Vance, C., Leclerc, A. L., Keagle, P., Glass, J. D., McKenna-Yasek, D., et al. (2011b). Mutational Analysis Reveals the FUS Homolog TAF15 as a Candidate Gene for Familial Amyotrophic Lateral Sclerosis. Am. J. Med. Genet. 156, 285-290. doi:10.1002/ajmg.b.31158

Trnka, F., Hoffmann, C., Wang, H., Sansevrino, R., Rankovic, B., Rost, B. R., et al. (2021). Aberrant Phase Separation of FUS Leads to Lysosome Sequestering and Acidification. Front. Cel Dev. Biol. 9, 716919. doi:10.3389/fcell.2021.716919

Tsai, P.-C., Liao, Y.-C., Jih, K.-Y., Soong, B.-W., Lin, K.-P., and Lee, Y.-C. (2018) Genetic Analysis of ANXA11 Variants in a Han Chinese Cohort with Amyotrophic Lateral Sclerosis in Taiwan. Neurobiol. Aging 72, e1-188. doi:10.1016/j.neurobiolaging.2018.07.002

Vahsen, B. F., Gray, E., Thompson, A. G., Ansorge, O., Anthony, D. C., Cowley, S. A., et al. (2021). Non-neuronal Cells in Amyotrophic Lateral Sclerosis - from Pathogenesis to Biomarkers. Nat. Rev. Neurol. 17, 333-348. doi:10.1038/ s41582-021-00487-8

Van Deerlin, V. M., Bekris, L. M., Bird, T. D., Yuan, W., Elman, L. B., Clay, D., et al. (2008). TARDBP Mutations in Amyotrophic Lateral Sclerosis with TDP-43 Neuropathology: a Genetic and Histopathological Analysis. Lancet Neurol. 7, 409-416. doi:10.1016/S1474-4422(08)70071-1

Van Treeck, B., Protter, D. S. W., Matheny, T., Khong, A., Link, C. D., and Parker, R. (2018). RNA Self-Assembly Contributes to Stress Granule Formation and Defining the Stress Granule Transcriptome. Proc. Natl. Acad. Sci. USA 115, 2734-2739. doi:10.1073/pnas.1800038115

Vance, C., Rogelj, B., Hortoba'gyi, T., De Vos, K. J., Sreedharan, J., Hu, X., et al. (2009). Mutations in FUS, an RNA Processing Protein, Cause Familial Amyotrophic Lateral Sclerosis Type 6. Science 323, 1208-1211. doi:10.1126/ science.1165942

Volkening, K., Leystra-Lantz, C., Yang, W., Jaffee, H., and Strong, M. J. (2009). Tar DNA Binding Protein of 43 kDa (TDP-43), 14-3-3 Proteins and Copper/zinc Superoxide Dismutase (SOD1) Interact to Modulate NFL mRNA Stability. Implications for Altered RNA Processing in Amyotrophic Lateral Sclerosis (ALS). Brain Res. 1305, 168-182. doi:10. 1016/j.brainres.2009.09.105

Wang, A., Conicella, A. E., Schmidt, H. B., Martin, E. W., Rhoads, S. N., Reeb, A. N., et al. (2018). A Single N-terminal Phosphomimic Disrupts TDP-43 Polymerization, Phase Separation, and RNA Splicing. Embo J. 37, e97452. doi:10.15252/embj.201797452

Wang, H., Kelley, F. M., Milovanovic, D., Schuster, B. S., and Shi, Z. (2021). Surface Tension and Viscosity of Protein Condensates Quantified by 
Micropipette Aspiration. Biophysical Rep. 1, 100011. doi:10.1016/j.bpr.2021. 100011

White, M. R., Mitrea, D. M., Zhang, P., Stanley, C. B., Cassidy, D. E., Nourse, A., et al. (2019). C9orf72 Poly(PR) Dipeptide Repeats Disturb Biomolecular Phase Separation and Disrupt Nucleolar Function. Mol. Cel 74, 713-728.e6. doi:10. 1016/j.molcel.2019.03.019

Winton, M. J., Van Deerlin, V. M., Yuan, W., Wood, E. M., Yu, C.-E., Schellenberg, G. D., et al. (2008). A90V TDP-43 Variant Results in the Aberrant Localization of TDP-43 In Vitro. FEBS Lett. 582, 2252-2256. doi:10.1016/j.febslet.2008. 05.024

Xiong, H.-L., Wang, J.-Y., Sun, Y.-M., Wu, J.-J., Chen, Y., Qiao, K., et al. (2010). Association between Novel TARDBP Mutations and Chinese Patients with Amyotrophic Lateral Sclerosis. BMC Med. Genet. 11, 8. doi:10.1186/1471-235011-8

Xue, Y. C., Ng, C. S., Xiang, P., Liu, H., Zhang, K., Mohamud, Y., et al. (2020). Dysregulation of RNA-Binding Proteins in Amyotrophic Lateral Sclerosis. Front. Mol. Neurosci. 13, 78. doi:10.3389/fnmol.2020.00078

Yan, J., Deng, H. X., Siddique, N., Fecto, F., Chen, W., Yang, Y., et al. (2010). Frameshift and Novel Mutations in FUS in Familial Amyotrophic Lateral Sclerosis and ALS/dementia. Neurology 75, 807-814. doi:10.1212/WNL. ob013e3181f07e0c

Yoshizawa, T., Ali, R., Jiou, J., Fung, H. Y. J., Burke, K. A., Kim, S. J., et al. (2018). Nuclear Import Receptor Inhibits Phase Separation of FUS through Binding to Multiple Sites. Cell 173, 693-705.e22. doi:10.1016/j. cell.2018.03.003

Yu, H., Lu, S., Gasior, K., Singh, D., Vazquez-Sanchez, S., Tapia, O., et al. (2021). HSP70 Chaperones RNA-free TDP-43 into Anisotropic Intranuclear Liquid Spherical Shells. Science 371, eabb4309. doi:10.1126/science.abb4309

Zhang, H., Elbaum-Garfinkle, S., Langdon, E. M., Taylor, N., Occhipinti, P., Bridges, A. A., et al. (2015). RNA Controls PolyQ Protein Phase Transitions. Mol. Cel 60, 220-230. doi:10.1016/j.molcel.2015.09.017
Zhang, K., Liu, Q., Liu, K., Shen, D., Tai, H., Shu, S., et al. (2018). ANXA11 Mutations Prevail in Chinese ALS Patients with and without Cognitive Dementia. Neurol. Genet. 4, e237. doi:10.1212/nxg.0000000000000237

Zhao, M., Kim, J. R., van Bruggen, R., and Park, J. (2018). RNA-binding Proteins in Amyotrophic Lateral Sclerosis. Mol. Cell 41, 818-829. doi:10.14348/molcells. 2018.0243

Ziltener, P., Rebane, A. A., Graham, M., Ernst, A. M., and Rothman, J. E. (2020). The Golgin Family Exhibits a Propensity to Form Condensates in Living Cells. FEBS Lett. 594, 3086-3094. doi:10.1002/1873-3468.13884

Zou, Z.-Y., Peng, Y., Feng, X.-H., Wang, X.-N., Sun, Q., Liu, M.-S., et al. (2012). Screening of the FUS Gene in Familial and Sporadic Amyotrophic Lateral Sclerosis Patients of Chinese Origin. Eur. J. Neurol. 19, 977-983. doi:10.1111/j. 1468-1331.2012.03662.x

Conflict of Interest: The authors declare that the research was conducted in the absence of any commercial or financial relationships that could be construed as a potential conflict of interest.

Publisher's Note: All claims expressed in this article are solely those of the authors and do not necessarily represent those of their affiliated organizations or those of the publisher, the editors, and the reviewers. Any product that may be evaluated in this article, or claim that may be made by its manufacturer, is not guaranteed or endorsed by the publisher.

Copyright $\odot 2022$ Milicevic, Rankovic, Andjus, Bataveljic and Milovanovic. This is an open-access article distributed under the terms of the Creative Commons Attribution License (CC BY). The use, distribution or reproduction in other forums is permitted, provided the original author(s) and the copyright owner(s) are credited and that the original publication in this journal is cited, in accordance with accepted academic practice. No use, distribution or reproduction is permitted which does not comply with these terms. 